\title{
Fragmentos de medicina medieval em Portugal: Frei Gil de Santarém e o Códice eborense CXXI/2-19
}

Tese de Mestrado em História, área de especialidade em História Medieval, apresentada à Faculdade de Letras da Universidade de Lisboa, Abril de 2017. Orientação da Professora Doutora Manuela Santos Silva

Ana Marta Silva Pinto

\section{C) OpenEdition}

1 Journals

Edição electrónica

URL: http://journals.openedition.org/medievalista/1683

DOI: $10.4000 /$ medievalista. 1683

ISSN: 1646-740X

Editora

Instituto de Estudos Medievais - FCSH-UNL

Edição impressa

Data de publição: 1 janeiro 2018

\section{Refêrencia eletrónica}

Ana Marta Silva Pinto, « Fragmentos de medicina medieval em Portugal: Frei Gil de Santarém e o Códice eborense CXXI/2-19», Medievalista [Online], 23 | 2018, posto online no dia 07 maio 2018, consultado o 23 setembro 2020. URL : http://journals.openedition.org/medievalista/1683; DOI : https://doi.org/10.4000/medievalista.1683

Este documento foi criado de forma automática no dia 23 setembro 2020.

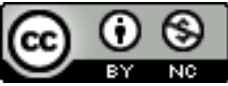

Mediavalista está licenciado com uma Licença Creative Commons - Atribuição-NãoComercial 4.0 Internacional. 


\section{Fragmentos de medicina medieval em Portugal: Frei Gil de Santarém e o Códice eborense CXXI/2-19}

Tese de Mestrado em História, área de especialidade em História Medieval, apresentada à Faculdade de Letras da Universidade de Lisboa, Abril de 2017. Orientação da Professora Doutora Manuela Santos Silva

\section{Ana Marta Silva Pinto}

\section{NOTA DO EDITOR}

Data recepção do texto / Received for publication: 23-06-2017

\section{A formação do "problema" e a estruturação do trabalho'}

1 A medicina da Europa medieval era composta por uma mescla de saberes herdados da Antiguidade, tradições orientais, árabes, judaicas e cristãs adicionados às práticas populares e ao cunho mágico-pagão trazido pelos variados povoadores da Europa pré medieva.

O estudo da história da medicina implica o olhar para as condições sociais, económicas, políticas e culturais. Esta história não se limita aos físicos, aos doentes, às doenças, mas também ao corpo, à religião, à história das universidades, às plantas e aos animais, à alimentação, ao clima e às estações do ano, entre tantos outros factores que influenciam o meio do homem medieval e, por conseguinte, os males que o afectam e as práticas combativas desses males. As perguntas surgem automaticamente. Afinal como era praticada a medicina em Portugal na Idade Média? Quem cuidava dos doentes? Onde os tratavam? Como eram feitos os diagnósticos e o que era usado para os seus tratamentos? Quais eram as principais doenças que afectavam o homem medieval e 
qual o seu prognóstico perante elas? E destas questões muitas outras vão surgindo; entre elas quais os livros usados para praticar medicina? Qual o cunho mágico agregado à medicina medieval? Seria esta medicina tão rudimentar e estaria tão longe de um pensamento científico como a conotação da "Idade das trevas" leva a crer? Estas e muitas outras interrogações acompanham o historiador de medicina medieval e, à medida que este se vai envolvendo nas páginas da história, vai percebendo que muitos outros campos influenciam a sua pesquisa. Foi com base nelas que iniciámos um processo de investigação para a realização de uma Tese de Mestrado intitulada Fragmentos de Medicina Medieval em Portugal: Frei Gil de Santarém e o Códice Eborense CXXI/ 2-19, com o propósito de transcrever o manuscrito, conhecer um pouco melhor a vida de Frei Gil como físico, perceber quais os principais compostos utilizados para a realização de mezinhas medievais, fazer um levantamento dos principais problemas de saúde referidos e da forma como eram abordados.

O nosso estudo compõe-se, então, de oito capítulos, incluindo um capítulo introdutório, estado da arte e conclusão. $O$ corpo do trabalho é acopmpanhado, ainda que de modo desigual, por um enquadramento teórico que permite uma melhor compreensão do documento analisado, abrangendo temáticas da medicina medieval não só num contexto mais geral, mas também mais específico. Assim, para o caso português, analizam-se as boticas medievais e a vida e obra de Frei Gil de Santarém, presumível autor da fonte indicada. $O$ último capítulo dedica-se ao Livro de Naturas, o objecto de estudo central, transcrito neste capítulo.

\section{Frei Gil de Santarém}

4 Envolto num contexto de mudanças socioculturais peninsulares dos séculos XII e XIII, Frei Gil, contemporâneo de Santo António de Lisboa e de Pedro Hispano, constitui também ele uma figura emblemática da nossa história. Representado pela ambiguidade religiosa entre o bem e o mal, tentado pelo Diabo, orientado pela Virgem Maria, manteve-se no limiar entre a ortodoxia e a heresia. Sinaliza a mudança da espiritualidade de uma península detentora de um cristianismo visigótico-bizantino, de cariz mediterrânico, oriental e andaluz, para um cariz europeu regido pelo papado romano, onde imperavam a vida cenobítica urbana, a aproximação às populações rurais e urbanas, característica da Baixa Idade Média. Frei Gil e os seus semelhantes lograram a elevação da medicina a um plano divino. E o seu enquadramento na escolástica medieval das universidades europeias permitiu maior visibilidade do campo e o seu aprofundamento ${ }^{2}$.

\section{A Fonte, o Códice Eborense CXXI/2-19}

O Códice Eborense CXXI/2-19, dada a marca de água registada, deverá ter sido escrito no final do século XV e comporta uma diversa cronologia em acervo, na área da medicina. São identificados onze livros diferentes, alguns dos quais atribuídos a Galeno, a Constantino (provavelmente Constantino Africano) e a Frei Gil de Santarém - livro sobre o qual recai a nossa investigação. Encontra-se escrito em português, a negro e com iniciais floreadas, verificando-se que está truncado ao começar no fólio número XII, com o capítulo número XIII. ${ }^{3}$ 
Dada a sua grande dimensão - trezentos e cinquenta fólios escritos, com um total de trezentas e setenta e quatro imagens digitalizadas, contando com capa, contra capa e folhas em branco - tornou-se necessária a seleção de apenas uma parte para a concretização do nosso estudo. Decidimo-nos pelos fólios atribuídos a Frei Gil de Santarém que, desde logo, nos cativou não só pela amplitude de ingredientes e doenças apresentados nas suas mezinhas, mas também por se tratar de uma personalidade importante da medievalidade portuguesa, cujo contributo no mundo médico foi pouco estudado.

7 Começámos pela transcrição do documento, que permitiu proceder à identificação dos problemas de saúde / doenças referidos e das plantas, ingredientes e componentes utilizados nas mezinhas. Foi identificada, na medida do possível, a origem destes ingredientes, que permitiu depois uma classificação repartida (maioritariamente) pelas seguintes categorias: animal, vegetal e mineral. Com estes dados, foram elaboradas tabelas que permitem identificar os principais problemas de saúde que afectavam o homem comum, dos mais variados sistemas, e resultantes das mais variadas situações, facultando ainda bastante informação sobre o impacto da doença no dia a dia do homem medieval.

Deve acrescentar-se que é inegável a importância Códice Eborense CXXI/2-19 como fonte de vocábulos específicos do português medieval, como já apontado por Mário Martins, S.J. ${ }^{4}$, que nos permitem uma aproximação à nomenclatura médica usada, bem como aos principais compostos das mezinhas medievais, na sua maioria plantas, nem todas conotadas atualmente como medicinais. As tabelas e o glossário que realizámos (ferramentas para facilitar o acesso ao conteúdo da fonte) tornam essa riqueza e variedade ainda mais claras.

$9 \mathrm{Na}$ análise das tabelas podemos verificar que as principais afecções referidas são compostas por problemas oculares; problemas relacionados com os dentes, com a digestão, com a cicatrização e com os ossos; maleitas resultantes de infecções e possibilidade de carências de hábitos de higiene; queimaduras, lesões por fraturas ou corpos estranhos; problemas relacionados com a saúde da mulher; problemas intestinais, como diarreia e obstipação; gota, afectando diversas zonas do corpo; febres, sem etiologia conhecida; diversas úlceras, bostelas, bubões, apostemas, tumores e cancro; afecções cutâneas; problemas do foro mental e problemas do foro mágicosupersticioso.

\section{Conclusões}

O estudo por nós desenvolvido, permitiu concluir que:

o Livro de Naturas compõe-se de uma grande quantidade de mezinhas e da descrição de sinais de morte ou de vida que nos familiarizam com a prática médica medieval. Não se tem ainda como certo que o seu autor fosse Frei Gil de Santarém. Vimos, pela enumeração dos sinais mortais ou "vidais", que este tipo de discurso médico era comum no contexto da medicina medieval, da mesma forma que nestes sinais e em outras passagens do livro podemos verificar a importância dos prognósticos. A riqueza da linguagem utilizada no texto dá-nos indicações de variados sintomas e doenças que preocupavam o homem medieval e que instigavam o físico na procura de um tratamento eficaz. A riqueza de informação sobre plantas, animais e outros 
ingredientes utilizados na composição destas mezinhas dá-nos uma indicação sobre a fauna e flora conhecidas. Através das doenças referidas, podemos identificar muitos problemas que nos acometem na atualidade, apesar de nem sempre serem identificadas com o nome que hoje lhes atribuímos. Outras inserem-se no contexto do quotidiano medieval e outras ainda não conseguimos encontrar significado elucidativo.

Certamente que muito fica por dizer e que, possivelmente, outros olhos retirariam outro tipo de informação desta fonte, no entanto, esperamos deixar com este estudo um fragmento das práticas de medicina em Portugal, durante a Idade Média, e um contributo para a escrita da história da medicina.

\section{NOTAS}

1. $O$ texto integral desta tese poderá ser consultado em: https://www.academia.edu/33446039/ Fragmentos_de_Medicina_Medieval_em_Portugal_Frei_Gil_de_Santarém_e_o_Códice_Eborense_CXXI_2-19 2. CUSTÓDIO, Jorge - "S. Frei Gil de Santarém, da Ordem dos Pregadores: Uma personalidade entre a Lenda, a Hagiografia e a História”. in CUSTÓDIO, Jorge (coord.) - S. Frei Gil de Santarém e a sua época. Santarém: Câmara Municipal de Santarém, 1997, pp. 20, 48.

3. SANTOS, Maria Leonor Ferraz de Oliveira Silva; OLIVEIRA, L. N. Ferraz - "Um testemunho do conhecimento teórico e prático da medicina portuguesa quatrocentista". in Actas do Congresso Comemorativo do V Centenário da Fundação do Hospital Real do Espírito Santo de Évora. Évora: Barbosa \& Xavier, LDA - Artes Gráficas, 1996, pp. 65-73.

4. Veja-se MARTINS, Mário - "O Códice Eborense CXXI/2-19 como repositório da linguagem médica do séc. XV”. Boletim de Filologia 19 (1960), pp. 95-103.

\section{AUTOR}

\section{ANA MARTA SILVA PINTO}

Universidade de Lisboa, Faculdade de Letras / Centro de História, 1600-214, Lisboa, Portugal

a.martinha@gmail.com 